\title{
Kavak odun atıklarından elde edilen peletlerin bazı yakıt özelliklerinin belirlenmesi
}

\section{Determination of fuel properties of wood pellet's made from poplar wood resudies}

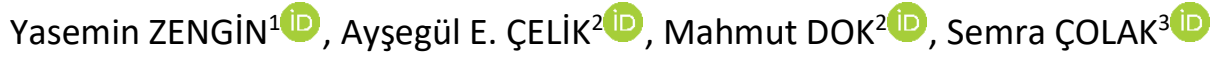 \\ ${ }^{1}$ Doğu Karadeniz Ormancılık Araştırma Enstitüsü Müdürlüğü TRABZON \\ ${ }^{2}$ Karadeniz Tarımsal Araştırma Enstitüsü Müdürlüğü SAMSUN \\ ${ }^{3}$ Karadeniz Teknik üniversitesi, Orman Endüstri Mühendisliği Bölümü TRABZON
}

Eser Bilgisi/Article Info

Araştırma makalesi/Research article DOI: $10.17474 /$ artvinofd. 556122

\begin{tabular}{l} 
Sorumlu yazar/Corresponding author \\
Yasemin ZENGIN \\
e-mail: yaseminzengin@ogm.gov.tr \\
\hline Geliş tarihi/Received \\
19.04.2019 \\
Düzeltme tarihi/Received in revised form \\
25.09.2019 \\
Kabul Tarihi / Accepted \\
06.10.2019 \\
Elektronik erişim/Online available \\
18.12.2019
\end{tabular}

Anahtar kelimeler:

Pelet

Kavak odunu

Biyokütle

Isıl Değer

Emisyon Değerleri

\section{Keywords:}

Pellets

Poplar wood

Biomass

Calorific value

Emissions values

\begin{abstract}
Özet
Günümüzde iklim değişikliği küresel ölçekte ciddi bir tehdit olarak karşımıza çıkmaktadır. Fosil yakıtların kullanımı sera gazı salınımlarını arttırmakta, bu da küresel ısınmaya neden olmaktadır. Her geçen gün enerjiye olan talebin artmasına karşın; fosil yakıt rezervlerinin hızla tükenmesi, fosil yakıtlar bakımından dışarıya bağımlı olmamız ve döviz kurlarındaki ani değişiklikler, fosil yakıtların çevresel olarak ciddi hasarlara sebep olması yenilenebilir enerji kaynaklarına olan ihtiyacı daha da önemli kılmaktadır. Orman atıkları, zirai atıklar ve bunun yanı sıra ülkemiz şartlarında kolaylıkla yetiştirilebilen ve hızlı büyüyen türlerden olan kavak odun artıklarının biyoyakıt olarak kullanılması büyük öneme sahiptir. Bu çalışmada; Bayburt yöresinden temin edilen karakavak (Populus nigra) atıkları KTÜ Orman Endüstri Mühendisliği pilot tesislerinde yongalanarak uygun boyuta getirildikten sonra, Karadeniz Tarımsal Araştırma Enstitüsü Müdürlüğü (KTAEM) biyokütle ünitesinde pelet üretimi gerçekleştirilmiştir. Üretilen peletlerin; ısıl değer, kül içeriği, nem oranının belirlenmesi, baca gazı emisyonlarının ölçülmesi ve elementel analizleri KTAEM. laboratuvarlarında yapılmıştır. Kavak odun atıklarından elde edilen peletlerinin ısıl değeri ve kül yüzdesi sırasıyla $18.91 \mathrm{MJ} / \mathrm{kg}$ (4515 cal/g) ve \%2.59 dur. N, C, H, O miktarları sırasıyla \%0.52, \%47.44, \%5.92 ve \%46.11 olarak bulunmuştur. Baca gazı emisyon değerleri; $\mathrm{O}_{2}, \mathrm{CO}_{2}, \mathrm{CO}, \mathrm{NO}, \mathrm{NO}_{x}, \mathrm{SO}_{2}$ sırasıyla \%15.70, \%5.06, 1279 ppm, 64 ppm, 66.67 ppm ve 23 ppm olarak tespit edilmiştir. Kavak odun atıklarından yapılan odun peleti; EN 14961-2'ye göre; nem içeriği, kül içeriği, ısıl değer, S (\%) ve N (\%) parametreleri bakımından EN-B kategorisinde yer almaktadır.
\end{abstract}

\begin{abstract}
Today, climate change is a serious threat on the global scale. The use of fossil fuels is one of the most important causes of global warming. Despite the increasing demand for energy every day; rapid depletion of fossil fuel reserves, in terms of its reliance on foreign fossil fuels and the need for renewable energy sources becomes even more important as fossil fuels cause serious environmental damage are making the need for renewable energy sources even more important. The use of poplar wood residues, which are easily grown in our own conditions and fast growing species, as biofuels has great importance. In this study; Poplar wood resudies were obtained from Bayburt. These materials chipped in the appropriate size at pilot plant of KTU Faculty of Forestry, Forest Industry Engineering. Pellets were produced in the biomass pellet production unit of the Black Sea Agriculture Research Institute Directorate. The produced pellets; calorific value, ash content, to determine the moisture content of the flue gas emission measurement and elemental analysis will be made in the Black Sea Institute of Agricultural Waste Management laboratory. The thermal value and ash content of the pellets obtained from poplar wood waste were $18.91 \mathrm{MJ} / \mathrm{kg}(4515 \mathrm{cal} / \mathrm{g})$ and $2.59 \%$ respectively. The amounts of $\mathrm{N}, \mathrm{C}, \mathrm{H}, \mathrm{O}$ were $0.52 \%, 47.44 \%, 5.92 \%$ and $46.11 \%$, respectively. The thermal value and ash content of the pellets obtained from poplar wood waste were $18.91 \mathrm{MJ} / \mathrm{kg}(4515 \mathrm{cal} / \mathrm{g})$ and $2.59 \%$ respectively. The amounts of $\mathrm{N}, \mathrm{C}, \mathrm{H}, \mathrm{O}$ were $0.52 \%, 47.44 \%, 5.92 \%$ and $46.11 \%$, respectively. The emission values of the flue gas $\left(\mathrm{O}_{2}, \mathrm{CO}_{2}, \mathrm{CO}, \mathrm{NO}, \mathrm{NO}_{x}, \mathrm{SO}_{2}\right)$ were also determined $15.70 \%, 5.06 \%, 1279$ ppm, $64 \mathrm{ppm}, 66.67 \mathrm{ppm}$ and $23 \mathrm{ppm}$ respectively. Wood pellets made of poplar wood waste; According to EN 14961-2; moisture content, ash content, thermal value, S (\%) and $\mathrm{N}(\%)$ in terms of parameters are in the EN-B category.
\end{abstract}

\section{GiRiş}

Nüfus artışı, kentsel gelişim ve sanayileşmeyle birlikte dünya enerji tüketimi de giderek artmaktadır. Yapılan projeksiyonlar 2040 yılında dünya nüfusunun 9 milyara yükseleceğini ve 2 milyar insana daha enerji arzı sağlanması gerekliliğini ortaya koymaktadır (Anonim 2015). Enerji ihtiyacı artmasına rağmen fosil yakıt rezervleri de gün geçtikçe tükenmektedir. Ülkemizde fosil yakıt olarak düşük kalorili linyit, taş kömürü, asfaltit, kok, 
petrol ve doğalgaz üretilmektedir. Üretilen kömürler termik santraller, demir çelik sanayi ve diğer sanayi kollarında kullanılmaktadır.

Bununla birlikte fosil yakıt kullanımının gerek çevresel gerekse ekonomik yönden pek çok sakıncası vardır. Fosil yakıtların kullanımı sonucu; ormanlık alanlar zarar görmekte, yer altı kaynakları tükenmekte, toprak, hava ve sular kirlenmektedir.

Fosil yakıtların sakıncalardan dolayı tüm dünya da olduğu gibi ülkemizde de yenilebilir enerji kaynakları arayışına gidilmiştir. Ülkemiz hidrolik, rüzgar, güneş ve biyokütle gibi önemli miktarlarda yenilebilir enerji kaynağına sahiptir.

Ülkemiz ormanlarında her yıl yapılan üretim ve bakım çalışmaları sonucu milyonlarca ton atık oluşmaktadır. Yaklaşık 7 milyon $\mathrm{m}^{3}$ kadar orman atığı ve tarımsal üretim sonrası yaklaşık 56 milyon ton zirai atık olduğunu bildirilmektedir (Saraçoğlu 2008). Atıl durumdaki bu atıkların pelet sektöründe kullanılma imkanlarının araştırılması ve bu atıklardan katma değerli ürünler elde edilmesi büyük öneme haizdir. Bunun yanı sıra kavak gibi hızlı gelişen türler kullanılarak endüstriyel ağaçlandırma sahaları kurulması biyokütle eldesi açısından önemlidir.

Odunsu biyokütle kullanılması durumunda yenilenebilir bir enerji kaynağıyla çevre sorunlarına çözüm bulunmuş olacaktır. Aynı zamanda fosil yakıtlar yerine biyokütle kullanılarak karbondioksit salınımı azaltılmış ve yaratılan iş sahasıyla kırsal kalkınmanın desteklenmesi sağlanacaktır. Endüstriyel olarak değerlendirilemeyen orman içi artıklar kullanılarak Türkiye'nin yenilenebilir enerjideki payı yaklaşık olarak \%2 arttırılabilir (Anonim 2009). Ayrıca Türkiye küresel iklim değişikliğiyle mücadelede 2030 yol haritasını belirlemiş olup, İklim Değişikliği ve Hava Yönetimi Koordinasyon Kurulu'nda alınan karar çerçevesinde 2030 yılında \%21'e kadar sera gazı emisyon azaltımı yapabileceğini karara bağlamıştır.

Biyokütle enerjisi Türkiye'de klasik yönteme dayanılarak, daha çok ticari olmayan yakıt biçiminde kullanılmakta ve yerli enerji üretiminin dörtte birini karşılamaktadır (Ültanır 1998). Demirbaş çalışmasında Türkiye'de 1999 yılında toplam 7 milyon ton olan biyokütlenin 2030 yılında
8.2 milyon ton olacağını belirtmiştir (Demirbaş 2006). Türkiye'de yenilenebilir enerji kaynakları açısından önemli bir potansiyel olmasına rağmen enerji talebinin yaklaşık $\% 80$ 'inin hala ithalat yoluyla karşılanıyor olması ve fosil yakıtların kullanımına bağlı olarak ortaya çıkan çevresel sorunlar yenilenebilir enerji kaynaklarının kullanımını ve bu kapsamda yapılacak olan araştırmaları zorunlu hale getirmektedir. Türkiye'de hammadde tedariki açısından orman kaynakları yeterli olup, elde edinimin ekonomik, ekolojik ve sosyal açıdan intilaf oluşturmadığı yerlerde, enerji üretimi amaçıı biyokütle kullanımı gereklidir (Eker ve ark. 2013, Alkan ve ark. 2014, Eker 2014).

Odun Peleti: odun artıklarının kurutulup, öğütülerek talaş haline getirildikten sonra yüksek basınçla sıkıştırılmasından elde edilen 6-10 mm çapındaki yakıt topaklarıdır. Kurutma, ögütme ve peletleme olmak üzere üç aşamadan oluşmaktadır. İlk aşamada yaklaşık \%50-65 arasında neme sahip olan odun tozu (talaş), yonga fırında kurutularak nem oranı yaklaşık \%10'a düşürülür. íkinci aşamada genellikle 6.4 ya da $3.2 \mathrm{~mm}$ çapa sahip değirmen eleğinden geçirilerek preslenir ve pelet haline getirilir. Yaklaşık 70-90 derece sıcaklıkta preslenen peletler soğutulma işlemiyle sıcaklıkları 25 dereceye düşürülür ve paketlenir (Magellia ve ark. 2009). Biyokütlenin ögütüldükten sonra yüksek basınç altında preslenerek sıkıştırılmasıyla pelet üretilmesi hem çevresel hemde maddi anlamda ülkeye katkı sağlanmaktadır.

Günümüzde enerji amaçlı kullanılan odun peleti uluslararası düzeyde büyük pazarı olan katı biyokütle yakıtlarından biri olup işlem hacmi bakımından biyodizel ya da biyoetanol ile karşılaştırılabilir duruma gelmiştir (Heinimö ve Jungınger 2009). Dünyada odun peleti pazarına Rusya, Kanada, Amerika ve Avrupa Birliği (EU-27) ülkeleri yön vermektedir. Başta Çin olmak üzere bir çok ülke alternatif enerji kaynakları ve özellikle odun peletinin üretimi, teknolojisi, kullanımı ve özellikleri üzerine çalışmalarını devam ettirmektedir (Wang ve Yan 2005, Eriksson ve ark. 2011, Telmo ve Lousada 2011, Uasuf ve Becker 2011). Pelet Avrupa'nın birçok ülkesinde 20 yıldır üretilmeye başlanmış ve günümüzde ise Avrupa'nın neredeyse tamamı, Kuzey Amerika, Rusya ve İskandinavya ülkeleri bu yakıt türünü kullanmaktadırlar. Finlandiya yakıt ihtiyacını \%96 oranında pelet yakıtından 
karşılamaktadır. (URL-2). Ülkemizde ise pelet üretimi yapan çok az sayıda fabrika bulunmakta olup bu fabrikaların birçoğu hammadde olarak odun tozu kullanmaktadır. Piyasadaki odun tozu bu sektörün hammadde ihtiyacını karşılayacak düzeyde olmayıp hammadde sıkıntısından dolayı mevcut fabrikaların da bir kısmı kapanmaktadır. Bu çalışma ile hızlı büyüyen türlerden olan ve ülkemiz şartlarında yetiştirilebilen kavak odun atıklarından pelet üretilerek, bazı yakıt özelliklerinin tespiti ve pelet üretimine uygun olup olmadığının belirlenmesi ve hammadde sıkıntısı yaşayan pelet sektörüne alternatif çözüm imkanları bulmak amaçlanmıştır. Bununla birlikte kavak üretiminin çoğunu özel sektör bir kısmını ise orman işletme müdürlükleri yapmakta ve net olarak ülkemizdeki yıllık kavak üretim miktarı bilinmemektedir. Böylelikle ülkemizdeki mevcut biyokütle kaynaklarına ek olarak program dahilinde hızlı büyüyen türlerle enerji ormanları kurulmasının gerekliliği ortaya koyulmuş olacaktır.

\section{MATERYAL ve YÖNTEM}

\section{Materyal}

Bu çalışmada; Bayburt ilinden temin edilen karakavak atıkları materyal olarak kullanılmıştır. Atıklar kavak odun üretimi sonucunda sahada kalan kullanılmayan odunsu materyalden oluşmaktadır. 2017 yılı mayıs ayında temin edilen odunsu atıklar hava kurusu hale gelene kadar bir süre açık havada bekletilmiştir. Daha sonra KTÜ Orman Fakültesi, Orman Endüstri Mühendisliği bünyesinde bulunan kaba yongalama makinesinde yongalanmıştır. Ardından materyal Karadeniz Tarımsal Araştırma Enstitüsü Müdürlüğü biyokütle ünitesine nakledilerek burada ince yongalama değirmeninden geçirilmiştir. İnce yongalanmıs materyal belli bir nem derecesine kadar kurutularak pelet üretimine hazır hale getirilmiştir. Peletleme işlemi Karadeniz Tarımsal Araştırma Enstitüsü Müdürlüğü (KTAEM) biyokütle ünitesinde gerçekleştirilmiştir. Peletleme işleminde; peletçapı: 6 $\mathrm{mm}$, motor gücü: $3 \mathrm{Kw}$, peletleme kapasitesi materyale göre değişmekle birlikte, $50-100 \mathrm{~kg} / \mathrm{h}, 380 \mathrm{~V}$ elektrikle çalışan, peletleme ünitesi dikey pozisyonda ve taşınabilir tip pelet makinesi kullanılarak yapılmışır. Odun peleti yapımında kullanılan kaba yongalanmış materyal şekil 1, odun peleti makinesi Şekil 2 ve üretilen odun peletleri şekil 3'te verilmiştir.

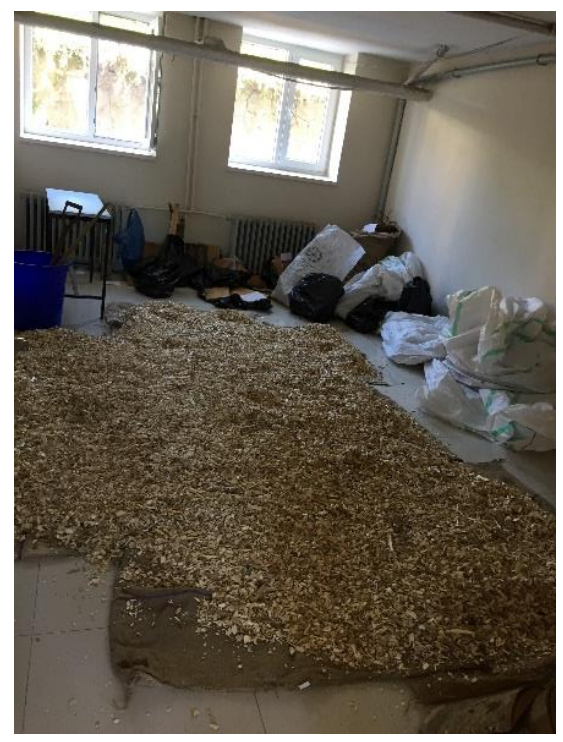

Şekil 1. Kaba yongalanmış materyal

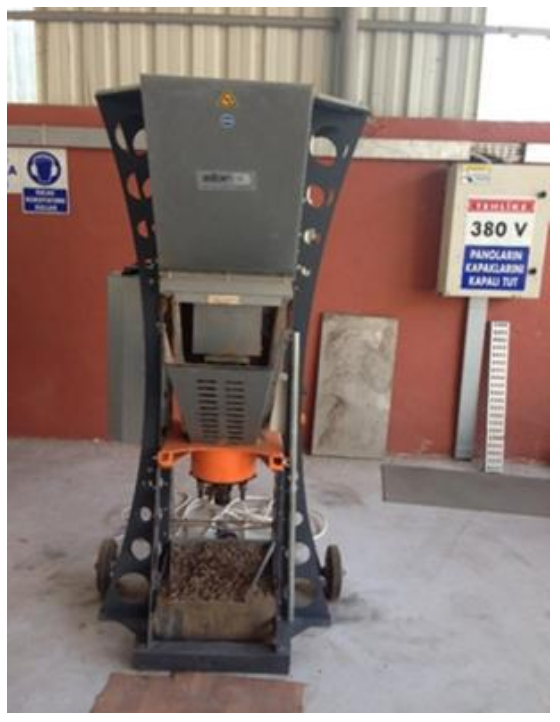

Şekil 2. Odun pelet makinası

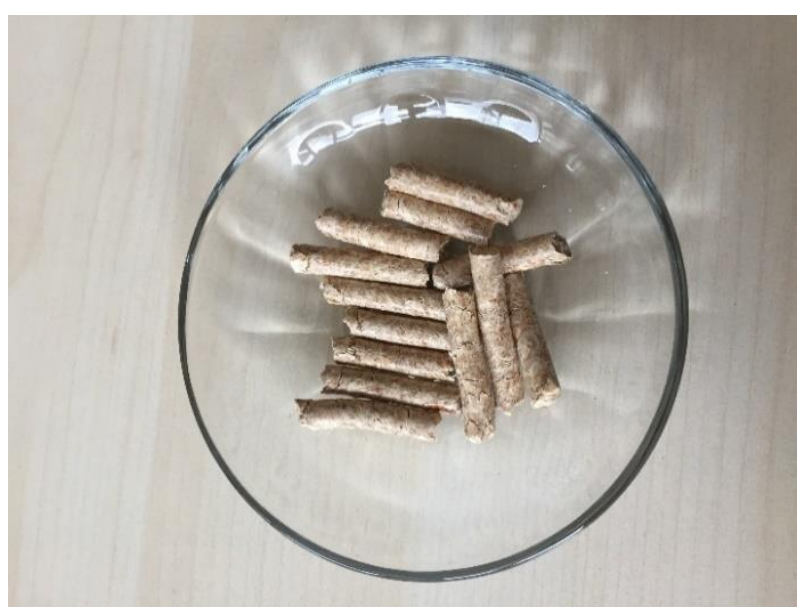

Şekil 3. Kavak odun peleti 
Hazırlanan peletler Karadeniz Tarımsal Araştırma Enstitüsü Müdürlüğü (KTAEM) laboratuvarında aşağıdaki analizlere tabi tutulmuştur. Pelet kalitesi ile ilgili bütün testler 3 tekerrürlü olarak yapılmıştır.

\section{Yöntem}

\section{Isıl Değerin Belirlenmesi}

Örneklerin alt ısıl değerleri, ASTM D 5865-04 standardına göre kalorimetre cihazı kullanılarak belirlenmiştir. Test öncesi öğütülmüş örnekler 24 saat $105^{\circ} \mathrm{C}^{\prime}$ de bekletilerek içerisindeki nem uzaklaştırılmıştır. $0.5 \mathrm{~g}$ ağırlığında kurutulan örnekler standart koşullarda bir kalorimetre bombasında oksijen ortamında yakılıp, kalorimetre kabı içindeki suyun sıcaklık derecesinin artışına ve sistemin ortalama gerçek ısı sığasına göre ısıl değer tayin edilmiştir. Yanma ısısı, yanma işleminden önce, yanma işlemi anında ve yanma işleminden sonraki sıcaklığın izlenmesi ve bunlara termo-kimyasal ve ISI değişimi düzeltmelerinin uygulanması ile hesaplanarak cal/g olarak kaydedilmiştir.

\section{Kül içeriğinin belirlenmesi}

Porselen krozeler $575 \pm 25^{\circ} \mathrm{C}^{\prime}$ de kül fırınında minimum 4 saat bekletilmiştir. Daha sonra desikatöre alınarak soğutulmuş ve tartım yapılmıştır. Tekrar kül fırınına yerleştirilip sabit ağırlığa gelmesi beklenmiştir. Porselen krozeler sabit ağırlığa ulaşınca 0.5-2 g örnek (etüvde kurutulmuş) tartılarak fırına yerleştirilmiştir. Fırın sıcaklığı oda sıcaklığından $105^{\circ} C^{\prime}$ ye yükseltilerek bu sıcaklıkta 12 dakika bekletilmiştir. Sıcaklık $10{ }^{\circ} \mathrm{C} /$ dakika artışla 250 ${ }^{\circ} C^{\prime}$ ye yükseltilerek bu sıcaklıkta 30 dakika, sıcaklık 20 ${ }^{\circ} \mathrm{C} /$ dakika artışla $575{ }^{\circ} \mathrm{C}^{\prime}$ ye yükseltilerek bu sıcaklıkta 180 dakika bekletilmiştir. Sıcaklığın $105{ }^{\circ}{ }^{\circ}$ 'ye düşmesi beklenerek krozeler desikatöre alınarak soğutulup tartılmış ve aşağıdaki formül yardımıyla kül içeriği hesaplanmıştır (NREL/TP-510-42622).

$$
\% K \ddot{u} l=\frac{A \breve{g} \iota r l l k_{K r o z e+K u ̈ l}-A \breve{g} \iota r l l k_{K r o z e}}{A \breve{g} \iota r l l k_{K u r u} \text { Örnek }} \times 100
$$

\section{Nem oranının belirlenmesi}

Darası alınan alüminyum kaplar $105 \pm 3^{\circ} \mathrm{C}^{\prime}$ deki etüvde en az 4 saat bekletilmiştir. Bu süre sonunda desikatöre alınarak soğutulup tartım yapılmıştır. Alüminyum kaplara 0.5-2 g örnek tartılıp ve $105 \pm 3{ }^{\circ} \mathrm{C}^{\prime}$ de etüvde sabit ağırlığa gelene kadar (genellikle 1 gece) bekletilmiştir. Daha sonra desikatöre alınarak soğutulmuş ve tartım yapılarak sonuç kaydedilmiştir (NREL/TP-510-42621).

$\% N e m=\frac{m_{2}-m_{3}}{m_{2}-m_{1}} \times 100$

$\mathrm{m}_{1}$ : Kurutulmuş boş kurutma kabın ağırlığı (g)

$\mathrm{m}_{2}$ : Analiz örneği + kurutma kabının ağırlığı (g)

$m_{3}$ : Analiz örneği + kurutma kabının kurutma işleminden sonraki ağırlığı (g)

\section{Elementel analiz}

Numunelerin C, H, N, S ve $\mathrm{O}$ tayini Thermo Marka Flash 2000 model elementel analiz cihazı ile yapılmıştır. Cihazın çalışma prensibi üç ayrı adımda tanımlanabilir (C, H, N, S için). İlk aşamada numune kalay (Sn) bir kapsüle konupv yakılarak yükseltgenmiştir. Sonuçta oluşan gaz karışımı, taşıyıcı inert bir gaz ile (He) bir kromatografi kolonuna gönderilmiştir. Burada Oksijen $\left(\mathrm{O}_{2}\right)$ gazı ile yakılarak oluşan ve ayrılan karışım gazları bir termokondüktif dedektöre (TCD) yönlendirilerek ayrılan her bir gazın miktarı ile orantılı bir elektrik sinyali elde edilmiştir. Bu elektrik sinyali daha sonra spektrumda elde edilen eğri alanlarıyla orantılanarak örneğin elementel bileşim yüzdesi tespit edilmiştir. Oksijen analizi için ise numune gümüş kapsül içinde cihaza verilerek piroliz sonucu oluşan gazın miktarı ile orantılı olarak elektrik sinyali elde edilmiştir. Diğer element analizindeki gibi numunedeki oksijen yüzdesi hesaplanmıştır (Krotz ve Giazzi 2010).

\section{Baca gazı emisyonlarının ölçülmesi}

Peletlerin yanma özelliklerinin ve çevresel etkilerinin belirlenmesi amacıyla yanma sonucunda oluşan baca gazı emisyon değerleri belirlenmiştir. Peletler, pelet yakma sobasında yakılmıştır. Yanma sonucu oluşan baca gazı emisyon (NOx, COx, SOx) değerleri ECOM EN2 marka bacagazı analizörü ile ölçülmüştür. 


\section{BULGULAR}

\section{Rutubet, kül, Isıl değer ve elementel analiz (C, H, N ve O tayini) değerleri}

Bayburt Orman İşletme Müdürlüğü'nden elde edilen odunsu atıklar, temmuz-ağustos ayı boyunca açık havada bırakılarak rutubet dengesinin hava kurusu hale gelmesi sağlanmıştır. Odun tozunun ve odun peletinin ortalama rutubet değerleri, kül bırakma miktarları, ısıl değerleri, elementel analiz sonuçları Çizelge 1 'de verilmiştir.

Çizelge 1: Kavak odun tozu ve kavak odun peletlerine ait nem, kül, Isıl değer ve elementel analiz (C, H, N ve O tayini) değerleri

\begin{tabular}{|c|c|c|c|c|c|c|c|c|}
\hline \multirow{2}{*}{ Materyal } & \multirow{2}{*}{ Rutubet (\%) } & \multirow{2}{*}{ Kül (\%) } & \multicolumn{2}{|c|}{ Isıl Değer } & \multirow{2}{*}{$\mathrm{N}(\%)$} & \multirow{2}{*}{ C (\%) } & \multirow{2}{*}{ H (\%) } & \multirow{2}{*}{ O (\%) } \\
\hline & & & $\mathrm{MJ} / \mathrm{kg}$ & $\mathrm{cal} / \mathrm{g}$ & & & & \\
\hline Odun Tozu (6 mm) & 4.98 & 2.27 & 19.23 & 4592 & 0.46 & 48.04 & 5.97 & 45.53 \\
\hline Odun Peleti & 6.02 & 2.59 & 18.91 & 4515 & 0.52 & 47.44 & 5.92 & 46.11 \\
\hline
\end{tabular}

Çizelge 1'de görüldüğü gibi odun tozunun rutubet ve kül bırakma yüzdeleri sırasıyla $\% 4.98$ ve $\% 2.27$ iken, odun peletinin \%6.02 ve \%2.59'dur. Odun tozunun ısıl değeri $19.23 \mathrm{MJ} / \mathrm{kg}$ (4592 cal/g) iken, odun peletinin $18.91 \mathrm{MJ} / \mathrm{kg}$ (4515 cal/g)'tir. Odun tozunun N, C, H, O miktarları sırasıyla \%0.46, \%48.04, \%5.97 ve \%45.53, odun peletinin ise $\% 0.52, \% 47.44, \% 5.92$ ve $\% 46.11$ olarak bulunmuştur.
S (\%) tayin limitinin altında olduğu için tespit edilememiştir.

\section{Baca gazı emisyon değerleri}

Odun talaşı, odun tozu ve odun peletinin baca gazı emisyon değerleri Çizelge 2'de verilmiştir.

Çizelge 2. Baca gazı emisyon değerleri

\begin{tabular}{lllllll}
\hline Materyal & $\mathrm{O}_{2}(\%)$ & $\mathrm{CO}_{2}(\%)$ & $\mathrm{CO}(\mathrm{ppm})$ & $\mathrm{NO}(\mathrm{ppm})$ & $\mathrm{NO}_{\times}(\mathrm{ppm})$ & $\mathrm{SO}_{2}(\mathrm{ppm})$ \\
\hline Odun Talaşı & 17.73 & 3.10 & 1410.00 & 48.33 & 50.67 & 17.33 \\
Odun Tozu & 19.10 & 1.80 & 2552.33 & 18.00 & 18.00 & 41.67 \\
Odun Peleti & 15.70 & 5.06 & 1279.00 & 64.00 & 66.67 & 23.00 \\
\hline
\end{tabular}

Çizelge 2'de görüldüğü gibi odun talaşının $\mathrm{O}_{2}, \mathrm{CO}_{2}, \mathrm{CO}$, $\mathrm{NO}, \mathrm{NO}_{x}, \mathrm{SO}_{2}$ gazı emisyon değerleri sırasıyla \%17.73, \%3.10, 1410 ppm, 48.33 ppm, 50.67 ppm ve 17.33 ppm, odun tozunun \%19.10, \%1.80, 2552.33 ppm, 18 ppm, 18 ppm ve $41.67 \mathrm{ppm}$ ve odun peletinin ise $\% 15.70, \% 5.06$, 1279 ppm, 64 ppm, $66.67 \mathrm{ppm}$ ve 23 ppm olarak bulunmuştur

\section{TARTIŞMA VE SONUÇ}

Bu çalışma sonucunda; kavak odun peletinin ısıl değeri ve kül miktarı sırasıyla $18.91 \mathrm{MJ} / \mathrm{kg}$ ve $\% 2.59$ dur. N, C, H, O miktarları sırasıyla \%0.52, \%47.44, \%5.92 ve \%46.11 olarak bulunmuştur. Baca gazı emisyon değerleri; $\mathrm{O}_{2}, \mathrm{CO}_{2}$, $\mathrm{CO}, \mathrm{NO}, \mathrm{NO}_{\mathrm{x}}, \mathrm{SO}_{2}$ ise sırasıyla \%15.70, \%5.06, $1279 \mathrm{ppm}$, 64 ppm, 66.67 ppm ve 23 ppm olarak tespit edilmiştir.

Kavak odun tozunun nem oranı \%4.98, kavak odun peletinin ise $\% 6.02$ olarak tespit edilmiştir. Orman gülü peletlerinde rutubet miktarı \%6.33, defnede \%6, kestanede $\% 6.08$, kayında $\% 9.5$, gürgende $\% 9.8$, meşede
$\% 10$, yalancı akasyada $\% 9.2$ ve ladinde $\% 0.4$ olarak tespit edilmiştir (Gündüz ve ark. 2016, Özgen ve ark. 2014). Toscano ve ark. (2014), tarafından yapılmış olan bir çalışmada ise kayın peletinin rutubet miktarı \%7, ladinin ise $\% 6.8^{\prime}$ tir. Elde edilen sonuçlar değerlendirildiğinde, kavak peletlerin nem değerleri bakımından iyi bir yakıt olduğu söylenebilir.

Kavak odun tozu ve odun peletinin kül miktarı sırasıyla \%2.27 ve \%2.59 olarak tespit edilmiştir. Orman gülü peletlerinde kül miktarı \%1.08, defnede $\% 1.4$, kestanede $\% 1.37$, kayında $\% 0.5$, gürgende $\% 0.5$, meşede $\% 1.4$, yalancı akasyada \%0.8 ve ladinde \%9.3'tür (Gündüz ve ark. 2016, Özgen ve ark. 2014). Sarıçamın gövde ve dal odunu üzerinde yapılan çalışmalarda kül içeriği bakımından; kabuksuz gövde odunu $\% 0.40$, kabuk $\% 2.55$, kabuklu gövde odunu \%0.62, kabuklu dal odunu \%1.03, ibreler \%2.35, dal ve gövde dahil bütün ağaç \%0.76 olarak belirlenmiştir (Hakkila ve ark. 1995, Nurmi 1993). Tomruğun kül içeriği \%0.5- 1.2, sarıçam odun talaşının 
$\% 0.6$, huş odun talaşının \%0.4-0.6, istihsal kesim atıklarının \%1.33, Avrupa ladini kesim atıklarının \%2.0-6.0, dip kütüğünün $\% 0.50$, söğüt odun yongasının $\% 1.7$, kabuklu sarıçam testere talaşının \%1.1, kabuksuz sarıçam testere talaşının $\% 0.08$, sarıçam kabuğunun $\% 1.70$, Avrupa ladini kabuğunun \%2.34- 2.80 ve huş kabuğunun \%1.60'dır (Taipale,1996, Tahvanainen, 1995). Odun atıklarında kül miktarı \%0.4-1, biçme atıklarında \%0.5-2, testere talaşında \%0.4-0.5, kontrplak atıklarında ise \%0.40.8 , sadece kabuk kullanılarak üretilen peletlerde $\% 2-3$, kabuksuz odun kullanılarak üretilen peletlerde \%0.2-0.4, orman atıkları kullanılarak üretilen peletlerde yaklaşık olarak \%2'dir (Impola 1998, Alakangas 2005). Shen ve ark. (2012) Chinese White poplar (Populus tomentosa Carr.), Larch (Larix gmelini (Rupr.) Rupr., Cypressus funebris Endl., Chinese Pine (Pinus tabulaeformis Carr.), Maple (Acer mono Maxim.)'nin üzerine yaptıkları çalışmada; kül içeriklerini sırasıyla $\% 0.90, \% 0.46, \% 1.47, \% 0.25$ ve 1.80 olarak tespit etmişlerdir. Toscano ve ark. (2014) tarafından yapılmış olan bir çalışmada kayın peletinin kül miktarı \%0.9, ladinin ise \%0.2'tir. Kızılçam hasat artıklarının üretilen peletlerin kül oranı $\% 4.91$ olarak bulunmuştur (Gökoğlu 2016). Yapılan çalışmalarda kabuk oranının artmasıyla kül miktarının arttığı görülmektedir. $\mathrm{Bu}$ çalışma sonucunda tespit edilen kül değerleri literatürle uyuşmaktadır.

Kavak odun tozu ve odun peletinin ısıl değeri sırasıyla $4592 \mathrm{cal} / \mathrm{g}$ (19.23 cal/g) ve $4515 \mathrm{cal} / \mathrm{g}(18.91 \mathrm{cal} / \mathrm{g})$ olarak tespit edilmiştir. Yapılan çalışmalar sonucunda odun atıkları ve biçme atıklarının kalori değeri $18.5-20 \mathrm{MJ} / \mathrm{kg}$, testere talaşı ve kontrplak atıklarının ise $19-19.2 \mathrm{MJ} / \mathrm{kg}$ arasında değişmektedir (Impola 1998, Alakangas 2005). Sarıçamın gövde ve dallarının üzerinde yapılan çalışmalarda kabuksuz gövde odununun kalori değeri $19.31 \mathrm{MJ} / \mathrm{kg}$, kabuğun $19.53 \mathrm{MJ} / \mathrm{kg}$, kabuklu gövde odununun $19.33 \mathrm{MJ} / \mathrm{kg}$, kabuklu dal odununun 20.23 MJ/ $\mathrm{kg}$, ibrelerin 21,00 MJ/ kg, dal ve gövde dahil bütün ağacın 19.56 MJ/ kg'dir (Hakkila ve ark. 1995, Nurmi 1993). Orman gülü peletlerinde; kalori değeri $19.8 \mathrm{MJ} / \mathrm{kg}$, defnede $18.5 \mathrm{MJ} / \mathrm{kg}$, kestanede $18.0 \mathrm{MJ} / \mathrm{kg}^{\prime}$ dır (Gündüz ve ark. 2016). Toscano ve ark. (2014)'e göre kayın peletinin Isıl değeri $16.89 \mathrm{MJ} / \mathrm{kg}$, ladinin ise 16.58 $\mathrm{MJ} / \mathrm{kg}$ 'dır. Telmo ve Lousada (2011), yumuşak ağaçların ısıl değerleri 19-20 MJ/kg, sert ağaçların ise 14-19 MJ/kg olarak tespit etmişlerdir. Gökoğlu (2016) tarafından (Pinus brutia Ten.) ormanları hasat artıkları üzerinde yapılan çalışmada ısıl değer $22.17 \mathrm{MJ} / \mathrm{kg}$ olarak belirlenmiştir. Kızılçamın reçinece çok zengin bir tür olmasından dolayı, yaptığımız çalışmada üretilen odun peletlerinden daha yüksek ısıl değere sahip olması beklenen bir durumdur. Bu çalışma sonucunda tespit edilen ısıl değerler literatürle uyuşmaktadır. İyi bir yakıtın en önemli kriterlerinden biri ısıl değerin yüksek olmasıdır. Buna göre kavak peletinin ısıl değer bakımından oldukça iyi bir yakıt olduğu söyleyebilir.

Fosil yakıtlardaki karbon oranı arttıkça kalori değeri ve bunun yanı sıra atmosfere salınan zararlı gaz oranları da artmaktadır. Genel olarak biyokütle yakıtların fosil yakıtlara göre kalori değerleri düşük olmasına rağmen yanmaları sonucu fosil yakıtlara kıyasla çevreye çok daha az sera etkisi ile iklim değişikliğine neden olan zararlı gazlar salmaktadırlar. Bu yüzden biyokütleden enerji üretimi giderek tüm dünyada yaygınlaşmakta ve pelet üretimiyle ilgili dünyada ve Türkiye'de pek çok bilimsel çalışma yapılmaktadır.

Kavak odun peletinin $\mathrm{N}, \mathrm{C}, \mathrm{H}, \mathrm{O}$ miktarları sırasıyla $\% 0.52$, $\% 47.44, \% 5.92$ ve $\% 46.11$ olarak bulunmuştur. S (\%) tayin limitinin altında olduğu için tespit edilememiştir. Black Poplar (Populus nigra L.)'ye ait N, C, H, O miktarları sırasıyla \%0.32, \%47.75, \%6.06, \%46.18 olarak belirlenmiştir (Shen 2014). Toscano ve ark. (2014)'e göre kayın peletinin karbon oranı \%50.8, hidrojen oranı \%5.7, azot oranı $\% 0.1$ ve oksijen oranı $\% 42.5^{\prime}$ tir. Kızılçam hasat artıklarının üretilen peletlerin $\mathrm{C}, \mathrm{H}, \mathrm{O}, \mathrm{N}$ miktarları ise sırasıyla \%47.52, \%5.15, \%42.16 ve \%0.26'dır (Gökoğlu 2016). Orman gülü peletlerinde; C $\% 53.37, \mathrm{H} \% 4.89, \mathrm{~N}$ \%0.27, O \%33.89, defne peletlerinde; C \%51.15, H \%4.94, $\mathrm{N} \% 0.32, \mathrm{O} \% 35.12$, kestane peletlerinde ise $\mathrm{C} \% 49.95, \mathrm{H}$ $\% 4.60, \mathrm{~N} \% 0.34,0 \% 38.08^{\prime}$ dir (Gündüz ve ark. 2016). Bu çalışma sonucunda belirlenen $\mathrm{N}(\%), \mathrm{C}(\%), \mathrm{H}(\%), \mathrm{O}(\%)$ ve $S(\%)$ değerleri literatürle uyumludur.

Kavak odun peletinin $\mathrm{CO}$ (ppm) değeri 1279 ppm, $\mathrm{CO}_{2}$ değeri ise \%5.06 olarak tespit edilmiştir. Isınmadan Kaynaklanan Hava Kirliliğinin Kontrolü Yönetmeliği'ne göre katı yakıtlı yakma tesislerinde CO (ppm) değeri 4003200 ppm, aynı tesislerde yakacak olarak odun yakıtlar ve 
bitkisel maddeler kullanımı için $\mathrm{CO}_{2}$ (\%) değerinin maksimum \%20. 3 olması gerekmektedir (Anonim 2005a). Buna göre kavak odun peletinin $\mathrm{CO}$ ve $\mathrm{CO}_{2}$ değerlerinin yönetmelikteki değerlere uygun olduğu görülmektedir.

Kavak odun peletinin $\mathrm{NO}(\mathrm{ppm})$ değeri $64 \mathrm{ppm}, \mathrm{SO}_{2}(\mathrm{ppm})$ değeri ise 23 ppm olarak belirlenmiştir. 2005 tarih ve 5346 sayılı "Yenilenebilir Enerji Kaynaklarının Elektrik Enerjisi Üretimi Amaçlı Kullanımına İlişkin Kanun'a göre biyokütlenin katı yakıt olarak kullanıldığı tesislerin sekonder hava beslemeli yakma sistemi özelliğine sahip olması gerekmektedir. Ayrıca NO 400 mg/ $\mathrm{Nm}^{3}$ (195 ppm), $\mathrm{SO}_{\times} 200 \mathrm{mg} / \mathrm{Nm}^{3}$ (70 ppm) baca gazı emisyon değerlerini sağlanması zorunludur (Anonim 2005b). Buna göre çalışma kapsamında üretilen peletlerin $\mathrm{CO}, \mathrm{CO}_{2}$, $\mathrm{NO}$ ve $\mathrm{SO}_{2}$ değerleri bakımından oldukça iyi yakıt olduğu söylenebilir.

Kavak odun atıklarından üretilen peletlerin; baca gazı emisyon değerleri $\left(\mathrm{O}_{2}, \mathrm{CO}_{2}, \mathrm{CO}, \mathrm{NO}, \mathrm{NO}_{\mathrm{x}}, \mathrm{SO}_{2}\right)$, elementel analiz sonuçları $(\mathrm{N}, \mathrm{C}, \mathrm{H}, \mathrm{O}, \mathrm{S})$, nem ve ısıl değer bakımından standart limit değerler içerisinde olduğu ve EN 14961-2'ye göre EN-B kategorisinde yer aldığı tespit edilmiştir. Sonuç olarak üretilen kavak odun peletinin kalite değerleri açısından uygun olduğu, biyoyakıt sektörünün sürdürülebilir ve güvenli hammadde tedariği açısından hızlı büyüyen türlerden yararlanması gerektiği düşünülmektedir.

\section{KAYNAKLAR}

Acar M, Gizlenci Ş, Dok M, Erdoğmuş M, Efendioğlu Çelik A (2016) Bazı tarımsal atık- artıklarının biyokütle kaynağı olarak değerlendirilmesi, 2. Ulusal Biyoyakıtlar Sempozyumu Bildiriler Kitabı, s.57, SAMSUN.

Alakangas E (2005) Properties of wood fuels used in Finland. Biosouth project, project report, $104 \mathrm{~s}$.

Alkan H, Korkmaz M, Eker M (2014) II. Ulusal Akdeniz Orman ve Çevre Sempozyumu Bildiriler Kitabı, s.608, 2014, Isparta

Anonim 2005a. Isınmadan kaynaklanan hava kirliliğini kontrolü yönetmeliği, 13.01.2005 tarihli resmi gazete sayısı: 25699

Anonim 2005b. Yenilenebilir enerji kaynaklarının elektrik enerjisi üretimi amaçlı kullanımına ilişkin kanun, kanun numarası: 5346 kabul tarihi: 10/5/2005 yayımlandığı r. gazete: tarih: 18/5/2005, sayı: 25819 yayımlandığı düstur: tertip: 5 cilt: 44

Anonim 2009. OGM Biyoenerji Komisyonu, Mayıs-2009 Ankara

Anonim 2015. Ocak 2015 itibarıyla Türkiye'nin enerji görünüm raporu, TMMOB Makine Mühendisleri Odası Bülteni, Şubat 2015, sayı 200 eki.

Demirbaş A (2006) Turkey's renewable energy facilities in the near future. Energy sources, part A 28, 527-536.
Eker M (2014) Trends in woody biomass utilization in Turkish forestry, croat. j. for. eng. 35 (2), 255-270.

Eker M, Acar H. H, Özçelik R, Alkan H, Gürleyik N, Çoban H.O, Korkmaz M, Yilmaztürk, A (2013) Ormancılıkta hasat artıklarının tedarik edilebilirliğinin araştırılması - sonuç raporu, TÜBITAK, project no:1100435, Ankara.

Eriksson G.L, Boman C, Bergsten U, Bergstöm D (2011) Fuel characterization of pellet chips, forest prod. J. 61 (2):143-148.

Gökoğlu C (2016) Kızılçam ormanları hasat artıklarından yapılan odun peletinin yakıt özelliklerinin belirlenmesi, Muğla Sıtkı Koçman Üniversitesi Fen Bilimleri Enstitüsü Yüksek Lisans Tezi.

Gündüz G, Saraçoğlu N, Aydemir D (2016) Characterization and elemental analysis of wood pellets obtained from low-valued types of wood, energy sources, part A: Recovery, utilization and environmental effects. volume 38, 2016- Issue 15.

Hakkıla P, Kalaja H, Saranpaa P (1995) Etela- Suomen Ensiharvennusmanniköt Kuitu- Ja Energialahteena. Helsinki, Finnish Forest Research Institute, research notes 582.

Heinimö J, Junginger H.M (2009) Production and trading of biomass for energy-an overview of the global status. Biomass Bioenergy 33 (9), 1310-1320, (2009).

Impola R (1998) Puupolttoaineiden Laatuohje. Jyvaskyla, FINBIO, Publication $5.33 \mathrm{p}$.

Krotz L, Giazzi G (2010) Biomass and bio-fuels characterization using the thermo scientific FLASH 2000 CHNS/O analyzer, application note: 42151

Magellia F, Boucher K, Bib H.T, Melin S, Bonolia A (2009) An environmental impact assessment of exported wood pellets from Canada to Europe, Biomass and Bioenergy 33, 434-441.

Nurmi J (1993) Pienkokoisten puiden maanpaallisen biomassan lampoarvo. Acta Forestalia Fennica 256. 28 p.

Özgen S, Caserini S, Galante S, Giugliano M, Angelino E, Marongiu A, Hugony F, Migliavacca G (2014) Emission factors from small scale appliances burning wood and pellets, Atmospheric Environment 94 (2014) 144-153.

Saraçoğlu N (2008) Modern enerji ormancılığı- ormanlardan biyokütle enerjisi üretimi ve çözümlemeler, Orman Genel Müdürlüğü toplantıSI, 19 Kasım 2008, ANKARA.

Shen $G$ (2014) Emission factors of carbonaceous particulate matter and polycyclic aromatic hydrocarbons from residential solid fuel combustions, DOI 10.1007/978-3-642-39762-2, Springer Verlag Berlin Heidelberg 2014.)

Shen G, Wei S, Wei W, Zhang Y, Min Y, Wang B, Wang R, Li W, Shen H, Huang $Y$, Yang $Y$, Wang W, Wang XI, Wang Xj, Tao S (2012) Emission factors, size distributions and emission inventoried of carbonaceous particulate matter from residential wood combustion in Rural China. Environmental Science Technology.2012.46 (7):4207-4214.

Tahvanainen L (1995) Pajun viljelyn perusteet. Basics of willow cultivation. Silva Carelica 30. University of Joensuu, Faculty of Forestry $86.126 \mathrm{p}$.

Taipale R (1996) Kiinteiden polttoaineiden ominaisuudet Jyvaskyla, University of Jyvaskyla, Master's Thesis. 138 P.

Telmo C, Lousada J (2011) Heating values of wood pellets from different species, Biomass and Bioenergy 35:2634-2639.

Toscano G, Duca D, Amota A, Pizzi A (2014) Emission from realistic utilization of wood pellet stove, Energy 68 (2014) 644-650.

Uasuf A, Becker G (2011) Wood pellets production costs and energy consumption under different framework conditions in Northeast Argentina. Biomass and Bioenergy 35,1357-1366.

URL-1, 2019. http://www.eigm.gov.tr/tr-tr/denge-tablolari/dengetablolari. Erişim 18.11.2019 
Kavak odun atıklarından elde edilen peletlerin bazı yakıt özelliklerinin belirlenmesi

URL-2, 2019. http://biomassmagazine.com/articles/9836/fao. Erişim 18.11.2019

Ültanır Ö (1998) 21. yüzyıla girerken enerji stratejisinin değerlendirilmesi, TÜsiAD-T/98-12/239, s. 142-146
Wang C, Yan J (2005) Feasibility analysis of wood pellets production and utilization in China as a substitute for coal. International Journal Of Green Energy, 2: 91-107. 